\title{
Conservation education promotes positive short- and medium-term changes in perceptions and attitudes towards a threatened primate species
}

\author{
Galicia Fernanda Bernárdez-Rodriguez ${ }^{1}$, Mark Bowler ${ }^{2,3,4}$, \\ Franciany Braga-Pereira ${ }^{1,5,6}$, Maxine McNaughton ${ }^{2}$ and Pedro Mayor ${ }^{1,7,8,9}$
}

\begin{abstract}
Many wildlife conservation projects aim to change the perceptions of local communities through conservation education programs. However, few assess whether and how these programs effectively promote shifts in community perceptions and attitudes towards wildlife conservation. We designed an educational program focused on communicating to local inhabitants from a remote community in the Peruvian Amazon that their territories are considered globally important for the red uakari (Cacajao calvus) and inspire them to become protectors and defenders of this endangered species. We aimed to evaluate changes in perceptions and attitudes towards the red uakari monkey after a conservation education workshop. We found that positive attitudes and perceptions towards the red uakari increased immediately after and in the short-term (two years) following the workshop but diminished in the medium-term (three years). However, even in the medium-term, attitudes remained better than before the workshop. Our results indicate that conservation education programs are useful in encouraging positive attitudes and perceptions towards wildlife conservation in the short term, but ongoing environmental education activities may be necessary to have lasting positive effects.
\end{abstract}

Keywords: Cacajao calvus; Conservation; Education Workshop; Perceptions Changes; Uakari; Monkey.

\footnotetext{
1 Departament de Sanitat i Anatomia Animals, Universitat Autònoma de Barcelona, Bellaterra, Spain.

2 School of Engineering, Science, Arts and Technology, University of Suffolk, Waterfront Building, Neptune Quay, Ipswich, UK.

3 Suffolk Sustainability Institute, Waterfront Building, Neptune Quay, Ipswich, UK.

4 Institute for Conservation Research, San Diego Zoo Global, Escondido, California, USA.

5 Department of Ecology and Systematics, Universidade Federal da Paraíba, João Pessoa, Paraíba, Brazil.

6 Rede de Pesquisa para Estudos sobre Diversidade, Conservação e Uso da Fauna na Amazônia (RedeFauna), Manaus, Amazonas, Brasil.

7 ComFauna, Comunidad de Manejo de Fauna Silvestre en la Amazonía y en Latinoamérica, Iquitos, Peru.

8 Museo de Culturas Indígenas Amazónicas, Iquitos, Loreto, Peru.

9 Programa de Pós-Graduação em Saúde e Produção Animal na Amazônia, Universidade Federal Rural da Amazônia, Belém, Pará, Brazil.

* Corresponding author $\bowtie$. E-mail address: PM (mayorpedro@hotmail.com, pedrogines.mayor@uab.es)
} 


\section{SIGNIFICANCE STATEMENT}

Although education programmes are a fundamental component of wildlife conservation, their effectiveness is often poorly documented. Assessments are rarer still in remote areas where conservation interventions are temporally shorter and less common. Through a community educational program aimed at inspiring local people to protect the red uakari monkey (Cacajao calvus), we communicated to local inhabitants of a remote area of the Peruvian Amazon that their territories are considered globally important for this threatened species - a difficult perception to acquire from a local perspective. We evaluated the effectiveness of the education program for changing perceptions towards the red uakari. We found that relatively short education programs can have a positive effect on conservation. However, encouraging positive perceptions and attitudes towards a species may be a slow process and, thus, conservation education programs may need continuity in the longer term to achieve lasting positive conservation outcomes.

\section{INTRODUCTION}

Wildlife conservation often hinges on local human populations' attitudes and actions (Kellert et al. 1996), and conservation programs often aim to raise local people's awareness and interest in the sustainable use or conservation of target species (Lee and Priston 2005; Remis and Hardin 2009). Education programs are frequently used to build local capacity, empower communities and develop successful conservation initiatives. While some projects have a long-term presence, use a highly engaging participatory approach (Aguilar 2018) and include longer-term assessments (Horwich and Lyon 2007; Liddicoat and Krasny 2013; Savage et al. 2010), many more are short-term projects funded by small grants, or are ephemeral, 'add-on' components of ecological research projects. These conservation education programs frequently have a relatively simple ‘top-down' pedagogical approach designed around the ease of administration, and they are often delivered by biologists rather than trained educators.

Although awareness campaigns and education programmes are a fundamental component of supporting wildlife conservation they are very rarely assessed, and their longer-term utility remains unclear (Bride 2006). There are a few good examples of evaluation of education programmes focused on primates: the cotton-top tamarin (Tamarin oedipus) in Colombia (Savage et al. 2010) and the black howler monkey (Alouatta pigra) in Belize (Horwich and Lyon 2007), and of research evaluating conservation education and community-based conservation more broadly (e.g., Ardoin 2006; Heimlich 2010). These programs incorporated interviews with local people on species at risk, environmental awareness, and research with short and long-term objectives, and involved the participation of private and governmental sectors. In these examples, such actions have increased target species populations and improved the life quality of the communities involved (Horwich and Lyon 2007; Savage et al. 2010). However, these projects are larger in scale and duration than many that are im- plemented globally. Despite the widespread use of education programs in raising interest in wildlife conservation in rural areas, the rarity of studies describing their effectiveness on local perceptions and conservation (Freund et al. 2020; Horwich and Lyon 2007) limits the understanding of their efficacy. Moreover, fewer still have assessed projects in very remote areas where high costs and difficult logistics may limit the scale and continuity of projects.

In this study, we seek to address this gap by evaluating the short and medium-term the effectiveness of a community education program for the conservation of the Peruvian red uakari (Cacajao calvus ucayalii) in a remote part of Peru. This subspecies is listed as Vulnerable by the IUCN, with populations that declined at least $30 \%$ over the past 30 years. This decline was primarily due to hunting and habitat loss, which reduced red uakaris to very patchily distributed populations (Bowler et al. 2009; Veiga et al. 2008).

Our study took place in the Yavari Mirin basin, characterized by relatively large populations of red uakari, persistent in part due to the area's remoteness from urban centers and the presence of malaria in the area (Bowler et al. 2013). However, in 2004, the Peruvian government designated forest concessions over the area, subcontracting people from local communities to extract timber (Mayor et al. 2015). Despite concerns about the impact of land-use change and hunting on uakari populations due the forest concessions, subsequent surveys found no evidence of declining primate populations on the Yavari Mirin (Mayor et al. 2015). However, the decline in populations of this species in other areas with logging operations urged precautionary measures to maintain their populations (Bowler et al. 2009). Thus, engagement programs were prescribed by our research group to better understand and change perceptions and attitudes which could threaten local populations of primates.

Intending to minimize the effects of wild meat hunting on uakari populations and increase the perception of importance of this species, we provided a conservation education program tailored towards local people in proximity to uakari populations. As part 
of this initiative, we evaluated the short and mediumterm changes in residents' perceptions and attitudes towards the uakari as a result of participating in this education program, using interviews conducted before and after the workshops.

\section{MATERIAL AND METHODS}

\section{Study area}

The study area covers 107,000 ha of continuous, predominantly upland forests along the Yavari-Mirin River in the north-eastern Peruvian Amazon (Figure 1). There is only one community within the study area, the Yagua community of Nueva Esperanza, with 329 inhabitants (159 men and 170 women) in 2015.

The Yagua people are distributed in a very dispersed way in the Peruvian Amazon. At the beginning of the 20th century, the Yagua were forced to labor during the rubber exploitation period. As a result, some groups migrated to other areas, extending their territory to the Yavarí River. In the 1950's, one mixed group of Yagua and non-Indigenous families founded the community of Nueva Esperanza, working mainly on the extraction of wild rubber (Hevea brasiliensis), the sale of wild animal skins, and the extraction of cedar (Cedrela odorata) timber and rosewood (Aniba rosaeodora) for its fragrant oils. In the 90's, the local residents of the community declined, and those remaining there lived primarily through subsistence activities. In 2004, a logging concession system in the region was approved, and foreign workers arrived, so the community grew demographically from 163 inhabitants to 329 inhabitants in 2015 . Thus, as of 2015, the community was of mixed origin ( $42 \%$ Yagua and 58\% non-Indigenous). Nueva Esperanza is officially designated as a Yagua indigenous community by the Peruvian government because many community members identify as this ethnicity. However, Spanish is the first language of all community members, and few uniquely Yagua traditions are maintained.

The villagers currently live through subsistence activities but trade timber, fish, wild meat, and agricultural products opportunistically. Accessibility to urban areas is difficult but has increased with more frequent logging traffic, facilitating the introduction of urban customs that require monetary income, such as electrical appliances. Thus, activities with an economic return, such as timber extraction, are attractive.

\section{Conservation education program}

We carried out two structured conservation education workshops in April and August 2014 with the vol- untary participation of local villagers. The workshops were conducted by hired specialists from the education sector in Iquitos, the main city in the Peruvian Amazon. These educators were previously trained in the local socio-cultural and ecological context of the region. Workshop participants were recruited through announcements at community meetings and over the local public address system used regularly and openly by the villagers. The workshops included a one-hour presentation and a translated (overdubbed from English into Spanish) version of a documentary about red uakari monkeys (Uakari: Secrets of the English Monkey 2009). This documentary focused on conservation issues related to natural resources, and featured the community of Nueva Esperanza, presenting them as guardians of the red uakari monkey and their habitat. The film appeared in 2009 on The Natural World, BBC, UK; Mutual of Omaha's Wild Kingdom, Animal Planet, USA; and The Nature of Things, CBC, Canada. Before showing the video, our team delivered an introductory presentation, discussing how community members were involved in the film and how the film had been featured on an international platform. Other sections of the workshops were particularly focused on characterizing the main traits of the red uakari, its habitat, distribution, the importance of conservation of primates, and the species' vulnerability to hunting. The workshops were presented in Spanish.

The focus group of our study was inhabitants from $>16$ years old, corresponding to 168 people (proportional to $51 \%$ of the community's total population, henceforth known as 'focus group', Additional File 1). From now on, percentages are related to the focus group, or when necessary, to the people interviewed. Sixty adults ( $36 \%$ of the total focus group) participated in one or more activities during the workshop, including 48 men ( $52 \%$ of focus men) and 12 women ( $16 \%$ of focus women). Although the invitation to participate in the workshops was extended to the entire community, fewer women attended than men, possibly due to their daily activities, including childcare. Alternatively, low participation by women could be because they did not perceive the topic as relevant to them, or they may have been reluctant to participate in activities or express opinions within the context provided (Engels and Jacobson 2007).

\section{Interview Protocol}

Semi-structured interviews were conducted to evaluate changes in hunting, perceptions, and attitude towards the red uakari following the workshops. In 2013, prior to the workshops, we conducted a control interview ( $\mathrm{N}=43,26 \%$ of the total focus group). This was followed by interviews immediately after the 


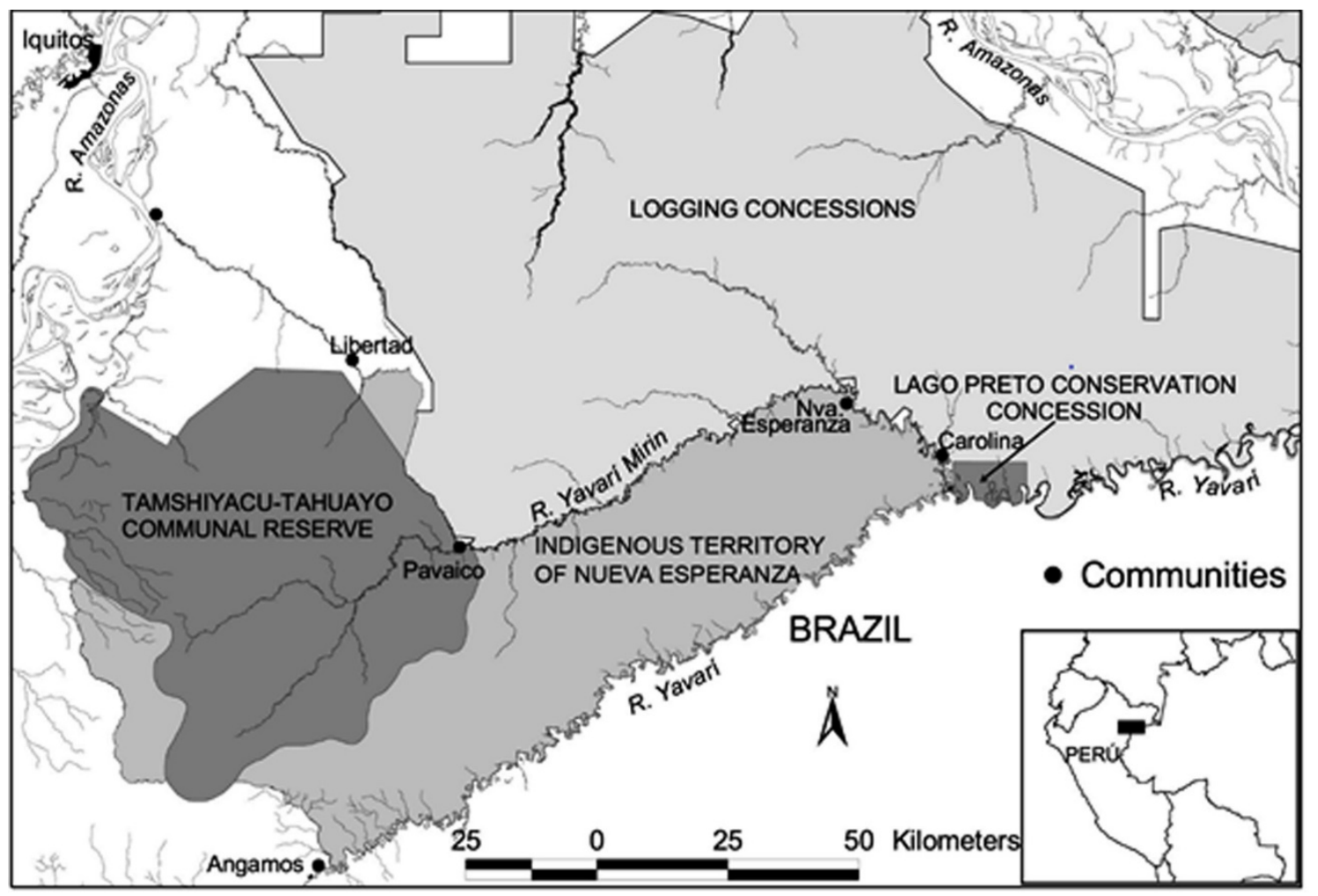

Figure 1. Map of the Community of Nueva Esperanza, Lago Preto Conservation Concession, and logging concessions on the Yavarí and Yavarí-Mirín Rivers with other critical areas for the conservation of red uakari.

workshops in $2014(\mathrm{~N}=52,31 \%), 2015(\mathrm{~N}=47,28 \%)$, and three years later in $2017(\mathrm{~N}=32,19 \%)$ (Table 1$)$. Interviewees were selected randomly by approaching local people to assess overall changes in the community. A total of 174 interviews were conducted to 124 people, of which $86(69.3 \%)$ were interviewed once, 26 $(21.0 \%)$ twice, and $12(9.6 \%)$ participated in three or four interviews.

From the control interview in 2013, surveys conducted in 2014, 2015, and 2017 explained the educational program's immediate, short- and medium-term effect, respectively. We considered the pool of responses each year as representative of perceptions in the community in that year. Thus, data are compared between years. The number of interviewees each year changed due to the varying availability of community members caused by the period of year in which interviews were conducted. For example, interviews in the years 2013, 2014, and 2015 were conducted in July-August. In contrast, the interview in 2017 took place in January-February, when logging activities are conducted outside the community for three or four months. This fact explains the lower participation in 2017.

Interviews were carried out by individual's unknown to the local population to reduce social desirability bias (Bergen and Labonte 2020). Interview- ers were biologists from the city of Iquitos and were external to the research group. In each year, a different interviewer was hired to conduct the interviews. Having interviews administered by people outside the community and not related to the project aimed to allow the interviewees to feel more comfortable giving their opinion without feeling that they were being judged and reduce any perception that responses should be consistent.

Participants were made comfortable with our interview process by informing them of the study aims before the interview. Respondents were free to participate in the study or leave it at any time and were informed that we would not disclose their identity. The research protocol was approved by the Research Ethics Committee at the Dirección General de Flora y Fauna Silvestre of Peru (0350-2012-DGFFSDGEFFS), and we followed the Guidelines for 'Applying Free, Prior and Informed Consent' in Buppert and McKeehan (2013). The applied questionnaire included sex and age information, diagnostic questions, and the main questionnaire (Table 1). Diagnostic questions were only conducted in 2013 to understand local perception towards de uakari.

The main questionnaire measured changes in local perceptions produced by the conservation education program. These questions were conducted before 
and after the workshop and included structured and semi-structured questions. Herein we include specific information on semi-structured questions:

1."Why do you/don't you consider the red uakari important?" We grouped responses into four categories: "Ecological importance" included answers about the ecosystem services provided by the red uakari and the importance of conserving their populations. "Food" included answers about the red uakari as a food item. "Personal feelings" referred to answers that indicated emotional attachment, distaste, the intrinsic value of the species, or personal experiences reflected in their answer. "Ecotourism" referred to the perceived potential of the uakari to attract tourists. Finally, we included the category "Don't know".

${ }^{2}$. In 2017 only (three years after the workshops), we asked 'What benefits could the conservation of the species provide to the local community?'. This question aimed to understand the perception of the benefits they obtain or want to obtain from the species conservation. Responses to this semi-structured question were grouped in three categories: "Ecological benefit", "Economical benefit" and "No direct benefit".

The answers to questions "Why do you/don't you consider the red uakari important?" and "What benefits could the conservation of the species provide to the local community?" were classified in common themes following Braun and Clarke (2006). Coded responses were summarized, and the frequency of each concept was quantified. This method of open-ended questioning provided the flexibility to explore different topics of relevance if necessary while providing rapid anthropological assessments valid for wildlife monitoring.

3. Some interviewed people expressed the expected economic benefits of conservation activities. To better understand these expected economic benefits, we asked each interviewee which activities they prefer to carry out and which ones they generally conduct as sources of income. This question had already been asked in 2009 for other research purposed; thus, we took advantage of this information to compare results between years.

\section{Data Analysis}

1) We performed generalized linear mixed models (GLMMs) and generalized linear models (GLM) to examine the effects of each predictor variable on responses to the questions "Do you consider the red uakari important?" (henceforth known as 'importance') and 'Do you or any of your relatives hunt the red uakari?' (henceforth known as 'hunting'). Since the responses regarding 'importance' and 'hunting' produced binary data (yes or no) we used binomial distribution.
For the first set of GLMMs, our predictor variables of fixed effect comprised (i) year of the interview (2013, 2014, 2015, and 2017); (ii) interviewee sex; (iii) interviewee age; (iv) hunting, which was used as a predictor variable only for the importance model; (v) importance, which was used as a predictor variable only for the hunting model. We used the interviewee as predictor variable of random effect. The reference category for the year variable used in both analyses was 2013 (control), so if 2014, 2015, or 2017 categories were significant, they were significant compared to 2013.

For the second set of GLMMs, the question "Why do you consider the red uakari important?" (henceforth known as "importance reasons') was used as a predictor variable of fixed effect. We used the interviewee as a predictor variable of random effect. Here we analysed the data of all years together. Finally, we performed a GLM using the 'importance reasons' as predictor variables to analyse data of each year separately and so also have a time frame of the predictor variable effect.

We used residual checks to verify whether our models were suitable or not in principle. Through Akaike information criterion we selected the model of interest if it had values of $\Delta \mathrm{AIC}>6(\Delta \mathrm{AIC}$ obtained when the AIC a null model was compared to the AIC of the complete model) (Harrison et al. 2018). All analyses were performed in $\mathrm{R}$ ver. 3.5.3 ( $\mathrm{R}$ Core Team 2019) using the Ggally, MuMin, lme4 and DHARMa packages. There was no collinearity $(p>0.05)$ among predictor variables.

2) We used simple linear regression to test for differences in people's answers regarding the "time since they last hunted red uakari" in pre (2013) and post (2014 and 2017) workshop interviews. In this model we only used data of people who reported hunting uakari. We selected the simple linear regression through the adjusted $\mathrm{r}^{2}, \mathrm{~F}$ value and the degrees of freedom.

3) We used the chi-squared test to: a) verify whether the proportion of responses citing each activity as "income-generating" is similar across different years; b) verify whether the proportion of responses citing each activity as "preferred" is similar across different years, and c) compare the similarity between the reported incomegenerating and preferred activities within each year. Our null hypothesis $(p<0.05)$ stated that there is no similarity; while our research hypothesis $(p>0.05)$ stated that there is a similarity. 
Table 1. Timeline of the study, including the workshop and the questionnaires conducted in the community of Nueva Esperanza in the Yavari Mirin basin, Peru.

\begin{tabular}{|c|c|c|c|c|c|c|}
\hline \multirow[t]{2}{*}{ Timeline } & \multirow{3}{*}{ Responses } & 2009 & 2013 & 2014 & 2015 & 2017 \\
\hline & & \multicolumn{2}{|c|}{ Before workshop } & Immediate effect & Short-term effect & Medium-term effect \\
\hline $\begin{array}{l}\text { Number of interviews (\% related to } \\
\text { the focus group) }\end{array}$ & & $68(40.5 \%)$ & $43(25.6 \%)$ & $52(30.9 \%)$ & $47(28.0 \%)$ & $32(19.0 \%)$ \\
\hline
\end{tabular}

the focus group)

\section{Diagnostic questionaire}

Do you think the uakari is in danger?

$$
\text { Yes/No }
$$

Do you know that the largest uakari popu- $\quad$ Yes/No

lations in the world are found in the Yavari

Mirin basin?

\section{Workshop}

\section{Main questionaire}

Do you consider the red uakari important? Yes/No

Why do you/don't you consider the red Semi-structured question uakari important? ${ }^{1}$

Do you or any of your relatives hunt the Yes/No red uakari?

When was the last uakari you, or your fam- Structured question ily members, hunted?

What benefits could the conservation Semi-structured question of the species provide to the local community? ${ }^{2}$

\section{Complementary questionaire}

Which activities the interviewee prefer to Semi-structured question 


\section{RESULTS}

The control interview conducted in 2013 showed that $25.5 \%$ of the local people in the Yavari Mirin basin thought that the uakari was in danger, and $16.3 \%$ knew that the largest uakari populations in the world are found in the Yavari Mirin basin. In addition, $32.5 \%$ perceived that the uakari is important, but $60.5 \%$ could not explain why, and $30.2 \%$ of families hunted the uakari.

When evaluating peoples' perceptions of the importance of the red uakari, we found an effect of the interview year, with an increase in interviewees that considered the red uakari important in the years post workshop, 2014 ( $E=1.28 ; p=0.00583), 2015$ $(E=3.22 ; p=6.14 E-07)$, and $2017(E=1.47 ; p=$ 0.00382 ), when compared to 2013 (pre workshop) (Figure 2). Significantly fewer people hunted uakari in $2014(E=-1.25 ; p=0.0322)$ and $2015(E=$ $-2.32 ; p=0.00678)$ when compared to 2013 , before the workshop. Although fewer hunted uakaris in 2017, the difference was not statistically significant $(E=-0.67 ; p=0.25672)$. The other predictor variables did not show effect on the response variable (Additional File 2).

When analyzing all years together, relationship of 'importance' and 'hunting' with 'importance reasons', we found that most people that said that the red uakari is important, did so most commonly because of personal feelings $(E=0.70651 ; p<2 e-16)$, followed by ecology $(E=0.6908, p<2 e-16)$, ecotourism $(E=0.68364 ; p=6.13 E-10)$, and food $(E=$ $0.56056 ; p=3.35 E-06)$. For people who hunted uakaris, the importance of the red uakari was significantly associated with their use as a food resource $(E=0.54507 ; p=4.25 E-06)$. When analysing the year separately, the importance of the red uakari was associated with the use as a food resource only for uakari hunters in $2013(E=3.091 ; P=0.0129)$, and with personal feelings only in $2014(E=4.7 ; p=$ $2.23 E-4)$ (Figure 3, Additional File 3).

We found a significant change $(E=44.84 ; p=$ $0.0104)$ in the time since interviewees reported they last hunted red uakari between 2013 (median $=6$ months; $\min =0.75, \max =180)$ and $2014($ median $=12$ months; $\min =1, \max =240$ ). The proportion of interviewees that had hunted red uakari within over one year diminished from $60.5 \%$ in 2013 to $23.0 \%$ in 2014. In 2017, the time since the last uakari (median $=24$ months; $\min =0.25, \max =204$ ) was hunted was not significantly larger than in previous years $(E=18.79 ; p=0.31)$; but the proportion of interviewees who had hunted red uakari within one year was reduced to $16.7 \%$. During our stays in the community, no uakari was observed hunted, nor was any spontaneous reference to hunting the species recorded.
A total of $65.6 \%(21 / 32)$ of interviewed people did not consider the red uakari a good prey because of its unpleasant taste or small size.

In 2017, we asked "What benefits could the conservation of the species provide to the local community?". A total of $69 \%$ of people interviewed perceived that the program provides benefits for the environment, but only $28 \%$ said there was a direct benefit to local people. We received a wide range of responses. The most frequently reported benefits were "attraction for tourists", "NGO support" and "sustainability of hunting and food security".

We evaluated changes in the activities preferred and engaged in by local people to better understand the effect of income generation strategies (Figure 4). We found a difference between years for the response pattern on the i) income-generating activities $\left(\mathrm{X}^{2}=102.86, \mathrm{df}=15, p-\right.$ value $\left.=3.743 e-15\right)$; and ii) preferred activities $\left(\mathrm{X}^{2}=208.81\right.$, df $=15$, $p-$ value $<2.2 e-16)$. When verifying if the activities that provide a higher income are reported with the same frequency of those cited as preferred in each year, we found a similarity between the activities only for the year of $2017\left(\mathrm{X}^{2}=8.2026\right.$, df $=5$, $p-$ value $=0.1454)$. In 2009, timber extraction was the preferred and economically most efficient activity for local people. From 2009 to 2017, although logging was still reported as the most frequent economic activity (ranging from $40 \%$ to $60 \%$ of responses), its preference diminished from $29 \%$ to $7 \%$ of respondents. Meanwhile, traditional subsistence activities, such as agriculture, fishing and hunting, were not frequently reported to generate income (overall averages of $11 \%$, $15 \%$ and $5 \%$ of responses, respectively). However, preference for agriculture and fishing increased considerably from 2009 onwards (from $11 \%$ to $28 \%$, and from $23 \%$ to $38 \%$, respectively), exceeding the preference for logging. On the other hand, preference for hunting remained constant at $20 \%$.

\section{DISCUSSION}

The main goal of our educational program was to communicate to local inhabitants that their territories are considered globally important for the uakari, a difficult perception to acquire from a local perspective, and to inspire them to become protectors and defenders of the species. The most abundant populations of the red uakari are found in their local area, where the species is infrequently hunted in the region because it does not provide a good return for the cost of a shotgun cartridge due to its small size relative to other species, such as hystricognath rodents and ungulates (Mayor et al. 2015). The interviews have helped us verify that the red uakari is not under very high hunting pressure in the Yavari Mirin 


\section{0}

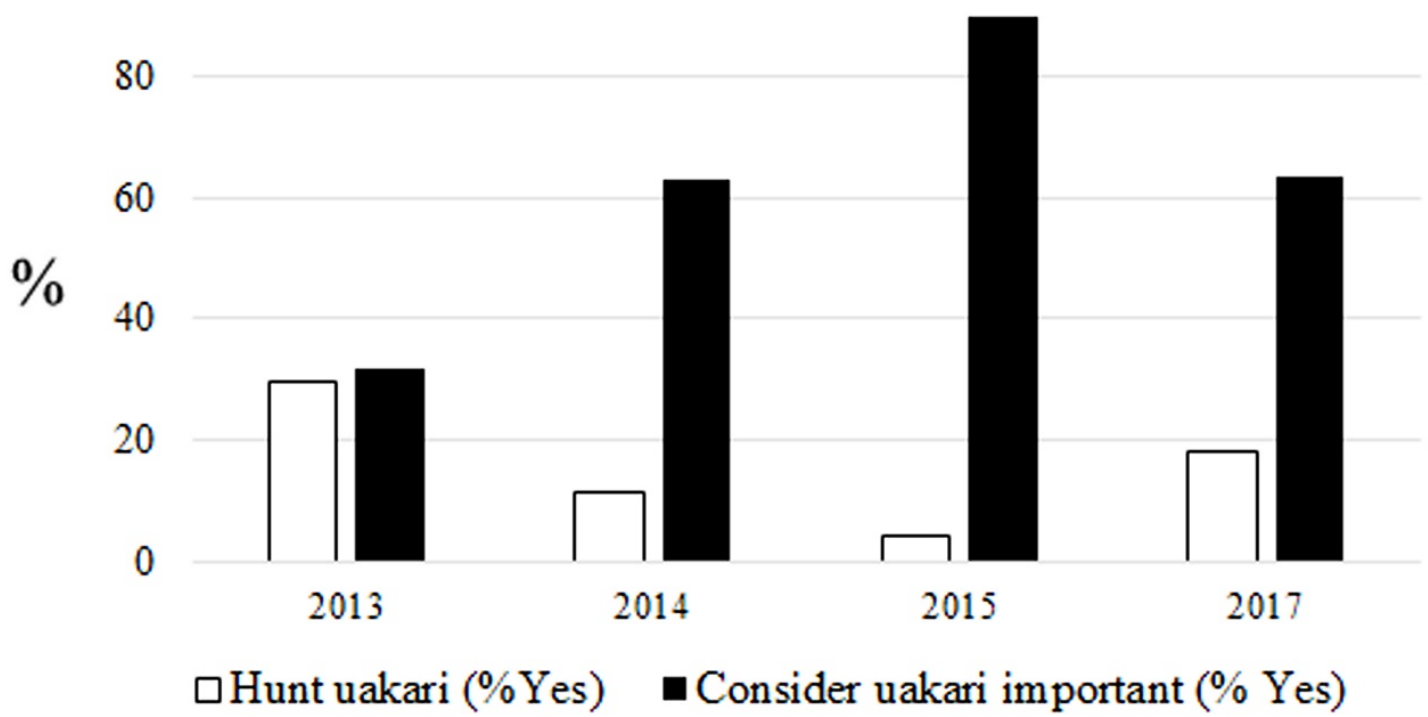

Figure 2. Percentage of interviewees who indicated that they or someone in their family hunted red uakari and who stated that they considered the red uakari important in 2013 before the educational programme, immediately after the education programme in 2014 and 2015, and in 2017, three years after the programme.

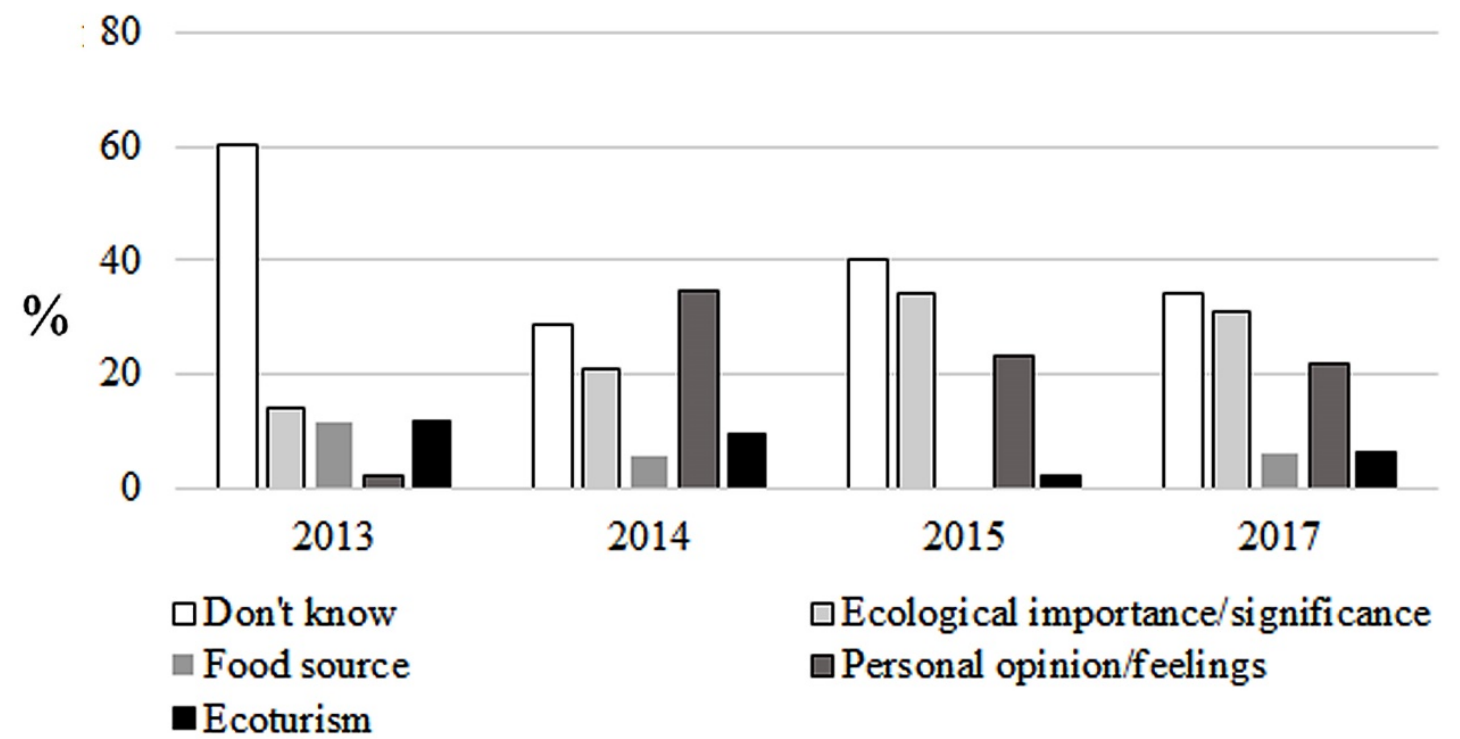

Figure 3. Responses (in percentage) to the open-ended question "Why do you/don't you consider the red uakari important?" asked in 2013 before the educational programme, immediately after the education programme in 2014 and 2015, and in 2017, three years after the programme. Responses were grouped into four categories.

basin despite the presence of logging activity. Many local people reported they would not hunt red uakari. Yet, some did occasionally hunt the species, suggesting hunting of red uakari may be opportunistic and related to the short-term necessity of finding food when hunts for larger prey have been unsuccessful (Puertas and Bodmer 1993). However, the red uakari is a vul- nerable species because their populations are highly fragmented and dispersed, and their reproduction is very slow (Mayor et al. 2017). In addition, the species has been extirpated from several other remote areas (Bowler et al. 2009), especially where logging operations have occurred. Therefore, this educational program aimed to encourage the residents to maintain 


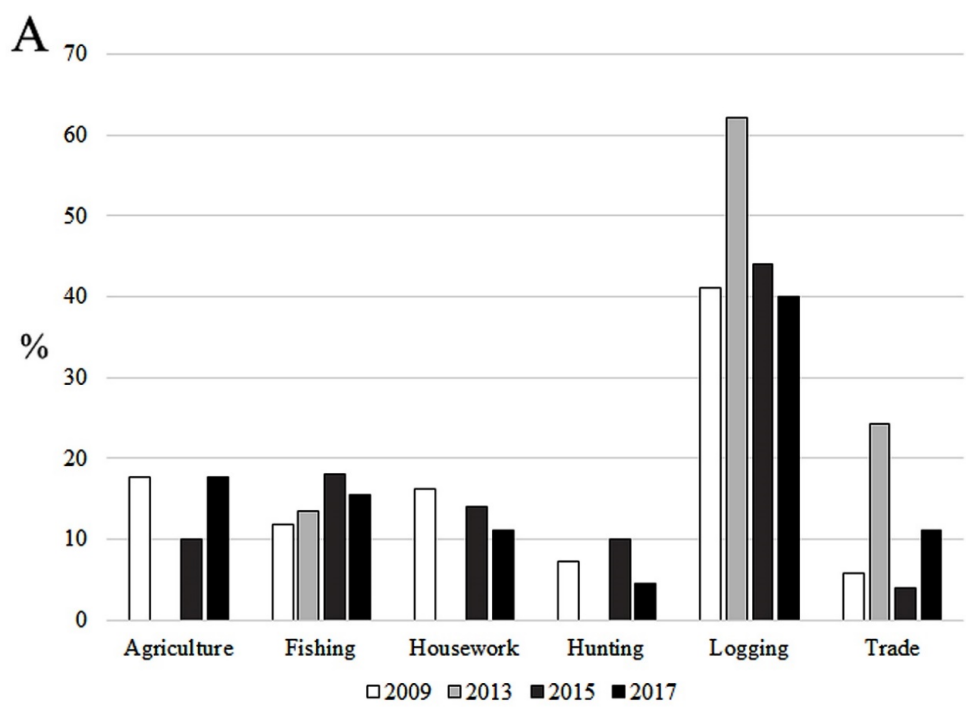

B 70

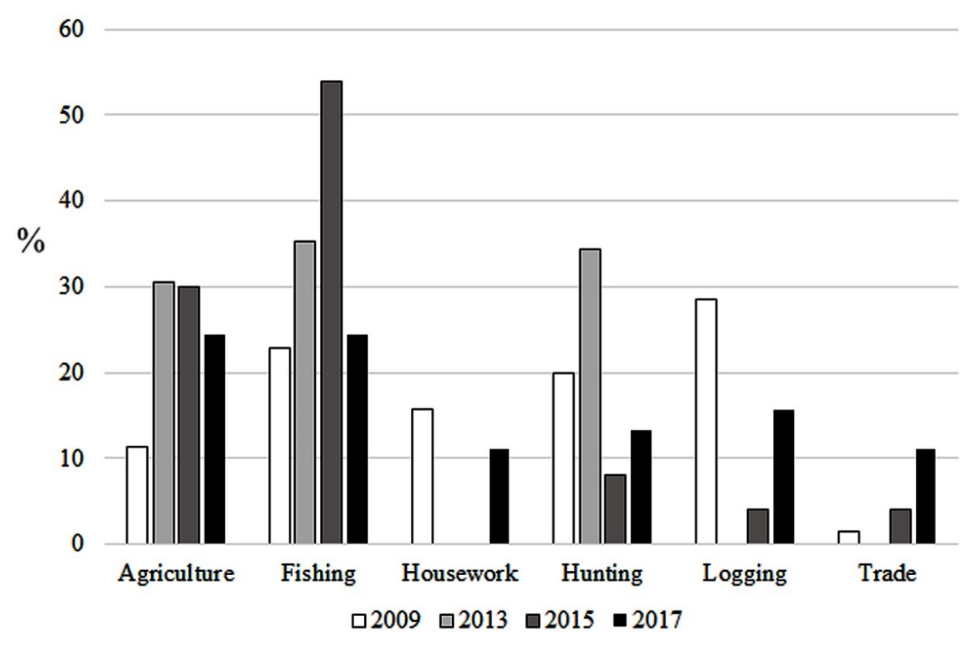

Figure 4. Responses (in percentage) to the open-ended questions (A) 'Activities to generate income', and (B) 'Activities they would prefer to do as a future alternative'. This question was conducted between 2013 and 2017, and also previously in 2009 .

practices that favor the conservation of the uakari.

The short-term nature of the conservation education program herein assessed is typical of those administered by short-term research and conservation projects. By measuring perceptions before and after implementing a specific educational program, we were able to illustrate the ability of an educational workshop to achieve short-term positive perceptions of a species. However, we found mixed results on medium-term outcomes. Although the educational program was largely typical of those commonly implemented in rural parts of the Amazon, it included a video focused on the red uakari, filmed mainly in and nearby the community, featuring various community members. This video was published on an international platform - a fact that was communicated to the community. The positive change in the behavior towards the uakari may be related to the film providing an opportunity for the local community to be seen internationally as actors in the species' conservation. This external recognition may have increased community members' beliefs that the species is important and that their efforts to conserve it will be valued (Danielsen et al. 2018). Therefore, care must be taken in applying these results to other scenarios and conservation education programs.

The changes in perceptions we observed were accompanied by a reduction in the number of people 
who said they hunted red uakari monkeys. In the medium term, the average period since respondents reported that they last hunted uakaris increased to more than a year. This fact suggests that the changes in hunting observed in the short term slightly diminished in the medium term.

Interviewees differed between years, but the bias associated to that could be controlled because the Nueva Esperanza community is small, and information is shared among the inhabitants, so we believe the sample interview is representative of opinions within the community. We recognize that our study was focused on over $16 \mathrm{~s}$ and had limited uptake by women. We believe it is necessary to engage younger people and women in conservation programs, promoting their incorporation and participation in activities that have not been traditionally directed to them. However, we do think our results are broadly applicable across at least adult demographics. Although there were no significant differences in perception change between age groups, younger adults experienced positive changes after the workshop and maintained this perception in the medium-term. In addition, young adults usually are more open-minded in developing new ideas than older generations (Ruiz-Mallen et al. 2010). In Nueva Esperanza, young adults represent active stakeholders in the use of natural resources, such as logging and hunting, so conservation programs should aim to engage their participation.

We show that relatively short education programs can have a positive effect on perceptions and attitudes expressed towards conservation. However, encouraging positive perceptions and attitudes towards a species may be a slow process. Thus, conservation education programs may need continuity in the longer term to achieve lasting positive conservation outcomes (Ruiz-Mallen et al. 2010). The decline in positive effects three years after our workshop suggests that it is reasonable to expect further decline through time. Furthermore, changes in perceptions and attitudes do not necessarily translate to changes in behaviour that will result in the conservation of species (Kuhar et al. 2010; Schultz 2011). To do that, uakari populations and hunting levels would have to be monitored through time.

Our results are consistent with other conservation education programs that have had an immediate positive impact that decreases over time (Hughes 2013), which is likely related to the short life span of the education program in the community. One of the main challenges in education programs is maintaining a channel of communication (Heimlich and Ardoin 2008). This fact has been observed in sustained successful projects like the Cotton-top Tamarin Project in Colombia (Savage et al. 2010), Colobus Spin Kenya (King and Lee 1987), or the Conservation Educa- tion Program carried out in Kalinzu Forest Reserve, Uganda (Kuhar et al. 2010). All of them had a constant presence over time and demonstrated positive long-term effects.

Aligning conservation objectives with the needs of local people and ensuring both the preservation wild species and the development of communities requires a broader approach. We found that people felt logging generated higher incomes when compared to other activities conducted in the area, explaining the prevalence of this activity. Probably because the Peruvian government encouraged logging over the area, this activity was the preferred and most crucial income-generating activity in the earlier operative years. However, preferences later returned to the traditional subsistence activities, such as hunting and fishing, either due to a decline in profitability or resources, or the strength of traditional values (Waylen et al. 2010). Future education and research programs should help the community to search or focus on activities they consider to be well remunerated and compatible with conservation.

\section{CONCLUSION}

One of the main criticisms of conservation education is that it emphasizes scientific facts, assuming that this acquisition of scientific knowledge will lead to the care and protection of wildlife (Russell 1999). However, conservation is a social process that engages science, not a scientific process that engages society (Adams and Sandbrook 2014). Therefore, beyond convincing and trying to impose our conservation ideals, our work aimed to inform the community about the broader global perceptions on uakari species and the local area, and understand local people's perceptions and attitudes regarding uakari post a conservation education workshop. The holistic understanding of landscapes and ecosystems by local communities and their local knowledge is relevant for conservation (Reyes-García 2009), but frequently ignored.

Our study included an internationally broadcast film that featured community members and their positive behaviors towards the uakari. Local people seeing external recognition of their conservation action may have been key to their attitudinal and behavioral changes towards the uakari; ultimately, this may have improved the outcome of the education program. The recognition of the value of local knowledge and the demonstration to local populations that their actions are important in conserving uakaris may have enhanced local peoples' desire to take care of this endangered species. 


\section{ACKNOWLEDGEMENT}

We thank all the people from Nueva Esperanza who participated in data collection, showing that communal participation is important in the development of wildlife management. We especially thank the National Commission of Science and Technology (CONACyT-342574) of Mexico for the scholarship provided during the investigation. We appreciate the essential help provided by Hani El Bizri and Joaquín Navarro in the review of the manuscript. This publication is funded in part by the Gordon and Betty Moore Foundation through Grant No. GBMF9258 to the Comunidad de Manejo de Fauna Silvestre en la Amazonía y en Latinoamérica (COMFAUNA).

\section{DATA AVAILABILITY}

The data used to support the findings of this study are available from the corresponding author upon reasonable request.

\section{CONFLICT OF INTEREST}

The authors have no conflicts of interest to declare.

\section{CONTRIBUTION STATEMENT}

$\mathrm{PM}$ and $\mathrm{MB}$ were responsible for idea conception and the study design. PM, MB and GFBR were responsible for the field work. FBP and MM contributed with the statistical analyses. GFBR, PM, $\mathrm{MB}$ and FBP contributed with the manuscript preparation.

\section{REFERENCES}

Adams WM, Sandbook C (2014) Conservation, evidence and policy. Oryx doi: 10.1017/S0030605312001470.

Aguilar OM (2018) Examining the literature to reveal the nature of community EE/ESD programs and research. Environmental Education Research doi: 10.1080/13504622.2016.1244658.

Ardoin NM (2006) Toward an interdisciplinary understanding of place: Lessons for environmental education. Canadian Journal of Environmental Education 11(1):112-126.

Bergen N, Labonté R (2020) "Everything is perfect, and we have no problems": detecting and limiting social desirability bias in qualitative research. Qualitative health research doi: $10.1177 / 1049732319889354$.
Bowler M, Noriega MJ, Recharte M, Puertas P, Bodmer R (2009) Peruvian red uakari monkeys (Cacajao calvus ucayalii) in the PacayaSamiria National Reserve a range extension across a major river barrier. Neotropical Primates doi: 10.1896/044.016.0108.

Bowler M, Valsecchi J, Queiroz HL, Bodmer R, Puertas P (2013) Communities and uacaris: Conservation initiatives in Brazil and Peru. In: Veiga L, Barnett A, Ferrari S, Norconk M (eds) Evolutionary Biology and Conservation of Titis, Sakis and Uacaris, eds. Cambridge University Press, Cambridge, UK, pp. 359-367.

Braun V, Clarke V (2006) Using thematic analysis in psychology. Qualitative Psychological Research doi: 10.1191/1478088706qp063oa.

Bride I (2006) The conundrum of conservation education and the conservation mission. Conservation Biology doi: 10.1111/j.15231739.2006.00544.x.

Buppert T, McKeehan A (2013) Guidelines for applying free, prior and informed consent: a manual for conservation international. Conservation International, Arlington, Virginia, USA.

Danielsen F, Burgess ND, Coronado I, Enghoff M, Holt S, Jensen PM, Poulsen MK, Rueda RM (2018) The value of indigenous and local knowledge as citizen science. In: Hecker S, Haklay M, Bowser A, et al. (eds) Citizen Science. UCL Press, London, UK, pp. 110-123.

Engels CA, Jacobson SK (2007) Evaluating LongTerm Effects of the Golden Lion Tamarin Environmental Education Program in Brazil. The Journal of Environmental Education doi: 10.3200/JOEE.38.3.3-14.

Freund CA, Achmad M, Kanisius P, Naruri R, Tang E, Knott CD (2020) Conserving orangutans one classroom at a time: evaluating the effectiveness of a wildlife education program for schoolaged children in Indonesia. Animal Conservation doi: $10.1111 /$ acv.12513.

Uakari: Secrets of the English Monkey (2009) Directed by Peter Von Puttkamer, Gryphon Productions.

Harrison XA, Donaldson L, Correa-Cano ME, Evans J, Fisher DN, Goodwin CE, Robinson BS, Hodgson DJ, Inger R (2018) A brief introduction to mixedeffects modelling and multi-model inference in ecology. Peer Journal doi: peerj.com/articles/4794.

Heimlich JE, Ardoin NM (2008) Understanding behavior to understand behavior change: a liter- 
Bernárdez-Rodriguez et al. 2021. Conservation education promotes positive short- and medium-term changes in perceptions and attitudes towards a threatened primate species

Ethnobio Conserv 10:31

ature review. Environmental Education Research doi: $10.1080 / 13504620802148881$.

Heimlich JE (2010) Environmental education evaluation: Reinterpreting education as a strategy for meeting mission. Evaluation and Program Planning doi: 10.1016/j.evalprogplan.2009.07.009.

Horwich RH, Lyon J (2007) Community conservation: practitioner's answer to critics. Oryx doi: 10.1017/S0030605307001010.

Hughes K (2013) Measuring the impact of viewing wildlife: do positive intentions equate to long-term changes in conservation behaviour? Journal of Sustainable Tourism doi: 10.1080/09669582.2012.681788.

Kellert S, Black M, Rush CR, Bath AJ (1996) Human culture and large carnivore conservation in North America. Conservation Biology doi: 10.1046/j.1523-1739.1996.10040977.x.

King FA, Lee PC (1987) A brief survey of human attitudes to a pest species of primate - Cercopithecus aethiops. Primate Conservation 8:82-84.

Kuhar CW, Bettinger TL, Lenhard K, Tracy O, Cox D (2010) Evaluating for Long-Term Impact of an Environmental Education Program at the Kalinzu Forest Reserve, Uganda. American Journal of Primatology doi: 10.1002/ajp.20726.

Lee PC, Priston NEC (2005) Human attitudes to primates: perceptions of pests, conflict and consequences for primate conservation. In: Paterson JD, Wallis J (eds) Commensalism and conflict: the human-primate interface. American Society of Primatologists, Norman, Oklahoma, USA, pp. 1-23.

Liddicoat K, Krasny M (2013) Research on the Long-Term Impacts of Environmental Education. In: Stevenson R, Brody M, Dillon J, Wals A (eds). International Handbook of Research on Environmental Education. Routledge/Taylor \& Francis, London, UK, pp. 289-297.

Mayor P, El Bizri H, Bodmer RE, Bowler M (2017) Assessment of mammal reproduction for hunting sustainability through community-based sampling of species in the wild. Conservation Biology doi: 10.1111/cobi.12870.

Mayor P, Perez-Peña P, Bowler M, Puertas PE, Kirkland M, Bodmer R (2015) Effects of selective logging on large mammal populations in a remote Indigenous territory in the northern Peruvian Amazon. Ecology and Society doi: 10.5751/ES08023-200436.
Puertas P, Bodmer R (1993) Conservation of a High Diversity Primate Assemblage. Biodiversity and Conservation doi: 10.1007/BF00051959.

R Core Team (2019) R: A language and environment for statistical computing. $\mathbf{R}$ Foundation for Statistical Computing. Vienna, Austria. [https://www.R-project.org] Accessed 14 July 2019.

Remis MJ, Hardin R (2009) Transvalued Species in an African Forest. Conservation Biology doi: 10.1111/j.1523-1739.2009.01290.x.

Reyes-García R (2009) Conocimiento ecológico tradicional para la conservación: dinámicas $\mathbf{y}$ conflictos. Revista Papeles 107:39-55.

Ruiz-Mallen I, Barraza L, Bodenhorn B, CejaAdame M, Reyes-Garcia V (2010) Contextualising Learning through the Participatory Construction of an Environmental Education Programme. International Journal of Science Education doi: 10.1080/09500690903203135.

Russell C (1999) Problematizing nature experience in environmental education: The interrelationship of experience and story. Journal of Experimental Education doi: $10.1177 / 105382599902200304$.

Savage A, Guillen R, Lamilla I, Soto L (2010) Developing an effective community conservation program for cotton-top tamarins (Saguinus oedipus) in Colombia. American Journal of Primatology doi: 10.1002/ajp.20770.

Schultz PW (2011) Conservation means behaviour. Conservation Biology doi: 10.1111/j.15231739.2011.01766.x.

Veiga LM, Bowler M, Silva Jr JS, Queiroz HL, Boubli JP, Rylands AB (2008) Cacajao calvus. The IUCN Red List of Threatened Species 2008: e.T3416A9846330. doi: 10.2305/IUCN.UK.2008.RLTS.T3416A9846330.en.

Waylen KA, Fischer A, McGowan PJK, Thirgood SJ, Milner-Gulland EJ (2010) Effect of local cultural context on the success of communitybased conservation interventions. Conservation Biology doi: 10.1111/j.1523-1739.2010.01446.x.

Received: 01 June 2021

Accepted: 29 July 2021

Published: 28 Semptember 2021 


\section{Additional Files}

Add File 1. Demographic description (in number and percentage) of the focus population of the Yagua indigenous community of Nueva Esperanza, people attending the workshops conducted in 2014, and the people interviewed from 2013 to 2017.

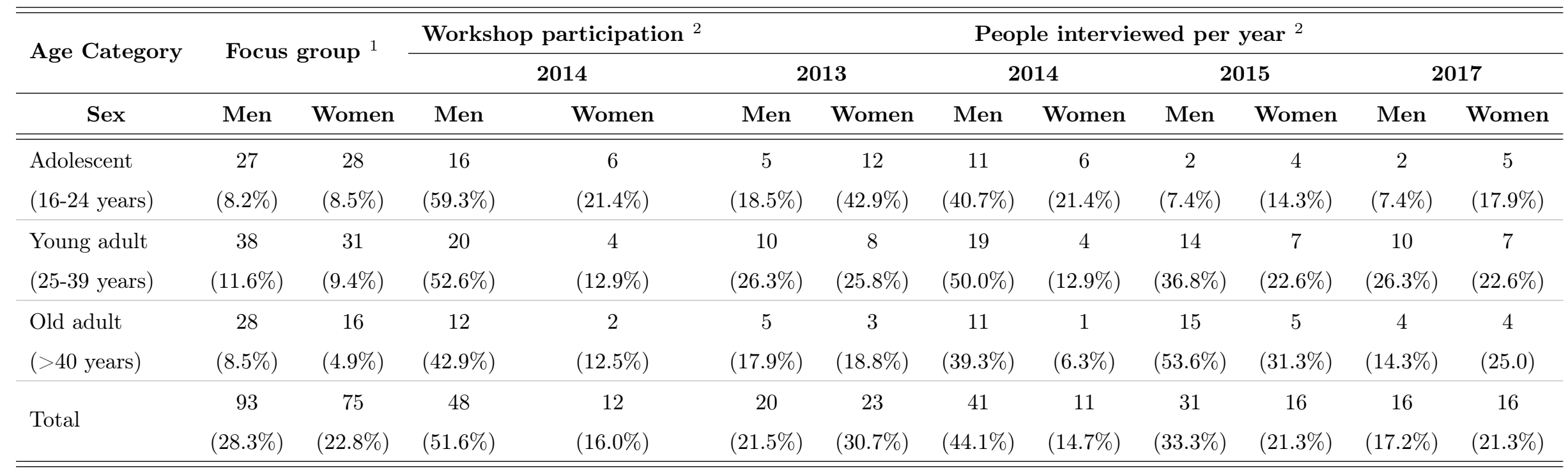

1 Percentages with respect to the total population census in $2015(\mathrm{~N}=329)$.

2 Percentages with respect to each focus sex-age group. 
Add File 2. Details of the complete model and the null model using GLMM to verify the influence of conservation education workshop and demographics variables on 'importance' and 'hunting' of red uakari in the community of Nueva Esperanza in the Yavari Mirin basin, Peru.

\begin{tabular}{|c|c|c|c|c|c|c|c|c|c|c|}
\hline $\begin{array}{l}\text { Response } \\
\text { variable }\end{array}$ & $\begin{array}{l}\text { Predictor } \\
\text { variables }\end{array}$ & Estimate & Std. Error & $\mathrm{z}$ value & $\operatorname{Pr}(>|z|)$ & & $95 \% \mathrm{CI}$ & $\mathrm{AIC}$ & $\begin{array}{c}\text { AIC } \\
\text { Null model }\end{array}$ & $\Delta \mathrm{AIC}$ \\
\hline \multirow{6}{*}{ Importance } & 2014:2013 & 1.28436 & 0.51311 & 2.503 & 0.0123 & $*$ & $0.278,2.290$ & 202.3 & 230.6 & 28.3 \\
\hline & $2015: 2013$ & 3.22884 & 0.751 & 4.299 & $1.71 \mathrm{E}-05$ & $* * *$ & \multicolumn{2}{|c|}{$1.756,4.700$} & & \\
\hline & $2017: 2013$ & 1.47571 & 0.59531 & 2.479 & 0.0132 & $*$ & \multicolumn{2}{|c|}{$0.308,2.642$} & & \\
\hline & female:male & -0.62731 & 0.39642 & -1.582 & 0.1135 & & \multicolumn{2}{|c|}{$-1.404,0.149$} & & \\
\hline & Age & -0.0154 & 0.01412 & -1.091 & 0.2755 & & \multicolumn{2}{|c|}{$-0.043,0.012$} & & \\
\hline & hunting & 0.22577 & 0.49165 & 0.459 & 0.6461 & & \multicolumn{2}{|c|}{$-0.737,1.189$} & & \\
\hline \multirow{6}{*}{ Hunting } & 2014:2013 & -1.25391 & 0.585423 & -2.142 & 0.0322 & $*$ & $-2.401,-0.106$ & 152.6 & 159.2 & 6.6 \\
\hline & $2015: 2013$ & -2.32046 & 0.857162 & -2.707 & 0.00679 & $* *$ & \multicolumn{2}{|c|}{$-4.000,-0.640$} & & \\
\hline & $2017: 2013$ & -0.67261 & 0.59303 & -1.134 & 0.25672 & & \multicolumn{2}{|c|}{$-1.834,0.489$} & & \\
\hline & female:male & -0.00196 & 0.475157 & 0.004 & 0.9967 & & \multicolumn{2}{|c|}{$-0.933,0.929$} & & \\
\hline & Age & -0.01243 & 0.018789 & -0.662 & 0.50811 & & \multicolumn{2}{|c|}{$-0.049,0.0243$} & & \\
\hline & hunting & 0.239059 & 0.492671 & 0.485 & 0.62751 & & \multicolumn{2}{|c|}{$-0.726,1.204$} & & \\
\hline
\end{tabular}


Add File 3. Details of the complete model and the null model using GLMM to verify the relation of 'importance' and 'hunting' to the 'importance reasons' in the community of Nueva Esperanza in the Yavari Mirin basin, Peru.

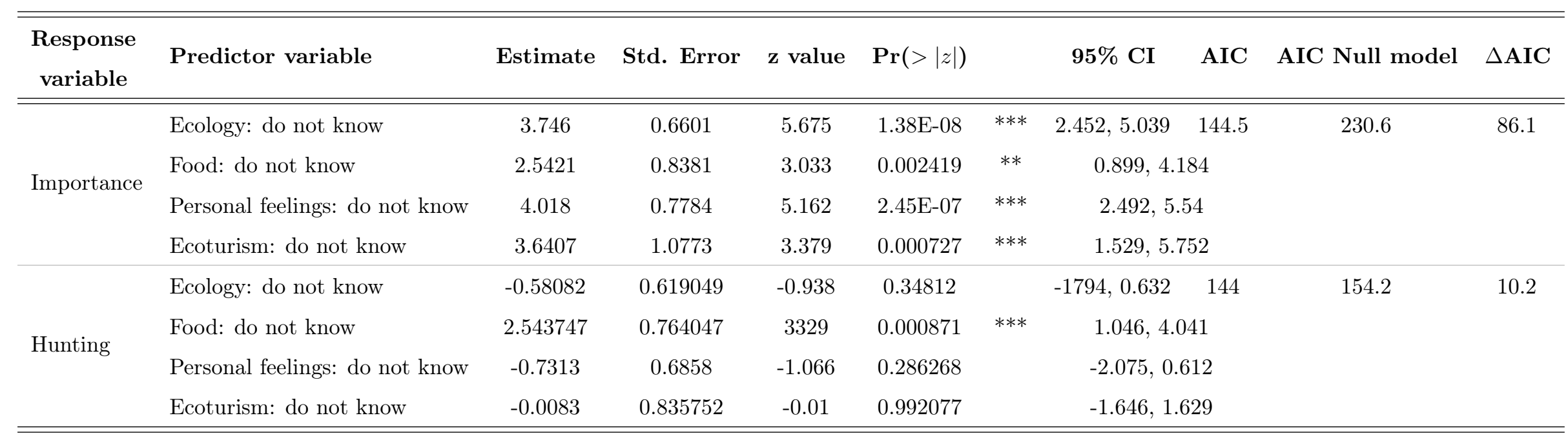




\begin{tabular}{|c|c|c|c|c|c|c|c|c|c|c|c|}
\hline & $\begin{array}{c}\text { Response } \\
\text { variable }\end{array}$ & Predictor variables & Estimate & Std. Error & $\mathrm{z}$ value & $\operatorname{Pr}(>|z|)$ & & $95 \% \mathrm{CI}$ & AIC & AIC Null model & $\Delta \mathrm{AIC}$ \\
\hline \multirow{4}{*}{2013} & \multirow{4}{*}{ Importance } & Ecology: do not know & 22.26 & 5732.95 & 0.004 & 0.997 & & $-1.176,3.010$ & 51.697 & 56.266 & .569 \\
\hline & & Food: do not know & 43.13 & 14274.94 & 0.003 & 0.998 & & $-0.915,6.212$ & & & \\
\hline & & Personal feelings: do not know & 43.13 & 29789.3 & 0.001 & 0.999 & & $-470.288,3.441$ & & & \\
\hline & & Ecoturism: do not know & 22.95 & 5732.95 & 0.004 & 0.997 & & $-0.938,3.417$ & & & \\
\hline \multirow{4}{*}{2014} & \multirow{4}{*}{ Importance } & Ecology: do not know & 22.205 & 3242457 & 0.007 & 0.994536 & & $-195.991,7.03$ & 33.725 & 69.083 & 35.358 \\
\hline & & Food: do not know & 1.946 & 1.604 & 1.213 & 0.224943 & & $-1.518,5.48$ & & & \\
\hline & & Personal feelings: do not know & 4.718 & 1278 & 3.691 & 0.000223 & $* * *$ & $2.585,7.924$ & & & \\
\hline & & Ecoturism: do not know & 22.205 & 4809.341 & 0.005 & 0.996316 & & $-442.441,7.22$ & & & \\
\hline \multirow{4}{*}{2015} & \multirow{4}{*}{ Importance } & Ecology: do not know & 1.034 & 1.209 & 0.855 & 0.3925 & & $-1.140,4.100$ & 32.056 & 29.36 & -32.027 \\
\hline & & Food: do not know & 17.89 & 3242 & 0.006 & 0.9956 & & $-4.209,3.330$ & & & \\
\hline & & Personal feelings: do not know & 17.89 & 10750 & 0.002 & 0.9987 & & $-2.169,1.020$ & & & \\
\hline & & Ecoturism: do not know & & & & & & & & & \\
\hline \multirow{4}{*}{2017} & \multirow{4}{*}{ Importance } & Ecology: do not know & 51.13 & 94377.21 & 0.001 & 1 & & $-6942.987, \mathrm{NA}$ & 10 & 43 & 33 \\
\hline & & Food: do not know & 51.13 & 166040.67 & 0 & 1 & & $-26019.615, \mathrm{NA}$ & & & \\
\hline & & Personal feelings: do not know & 51.13 & 104434.74 & 0 & 1 & & $-9320.382, \mathrm{NA}$ & & & \\
\hline & & Ecoturism: do not know & 51.13 & 166040.51 & 0 & 1 & & $-26019.589, \mathrm{NA}$ & & & \\
\hline \multirow{4}{*}{2013} & \multirow{4}{*}{ Hunting } & Ecology: do not know & 1.0116 & 1.0225 & 0.989 & 0.32248 & & $-1.176,3.0107$ & 51.697 & 57.703 & 6.006 \\
\hline & & Food: do not know & 3.091 & 1.2432 & 2.486 & 0.0129 & $*$ & $0.9159,6.212$ & & & \\
\hline & & Personal feelings: do not know & 18.2708 & 2399.5448 & 0.008 & 0.99392 & & $-4.702,1.72$ & & & \\
\hline & & Ecoturism: do not know & 1.2993 & 1.0624 & 1.223 & 0.22136 & & $-0.938,3.417$ & & & \\
\hline \multirow{4}{*}{2014} & \multirow{4}{*}{ Hunting } & Ecology: do not know & -18.1798 & 3242.457 & -0.006 & 0.9955 & & $-0.541,5.358$ & 36.555 & 39.193 & 2.638 \\
\hline & & Food: do not know & 2.0794 & 1.3844 & 1.502 & 0.1331 & & $-4.520,0.737$ & & & \\
\hline & & Personal feelings: do not know & -1.4469 & 1.2147 & -1.191 & 0.2336 & & $-0.741,4.934$ & & & \\
\hline & & Ecoturism: do not know & -18.1798 & 4809.3409 & -0.004 & 0.997 & & $-0.541,5.358$ & & & \\
\hline \multirow{3}{*}{2015} & \multirow{3}{*}{ Hunting } & Ecology: do not know & -18.426 & 4432.5925 & -0.004 & 0.9967 & & $-0.287,7.08$ & 20.787 & 18.542 & -2.245 \\
\hline & & Personal feelings: do not know & -18.426 & 5345.9077 & -0.003 & 0.9972 & & $-2.183,8.576$ & & & \\
\hline & & Ecoturism: do not know & -18426 & 17730.3699 & -0.001 & 0.9992 & & $-4.520,3.583$ & & & \\
\hline \multirow{4}{*}{2017} & \multirow{4}{*}{ Hunting } & Ecology: do not know & 0.1178 & 1.1118 & 0.106 & 0.9156 & & $-2.1831,2.421$ & 38.953 & 32.885 & -6.068 \\
\hline & & Food: do not know & 1.5041 & 1.6159 & 0.931 & 0.352 & & $-1.979,5.055$ & & & \\
\hline & & Personal feelings: do not know & -0.2877 & 1.3333 & -0.216 & 0.8292 & & $-3.482,2.269$ & & & \\
\hline & & Ecoturism: do not know & -16062 & 2797442 & -0.006 & 0.9954 & & $-0.541,33.417$ & & & \\
\hline
\end{tabular}

